\title{
ENGEVISTA
}

Página da revista: http://www.uff.br/engevista/seer/

\section{Otimização e redução do teor de óleo residual em uma planta de extração de óleo de soja}

\author{
Kamila Ayumi Costa Yoshimura ${ }^{1}$ \\ Eduardo Rasi de Almeida Prado ${ }^{2}$
}

Resumo: Este artigo visa a relatar as alterações realizadas em uma planta de tratamento de óleo vegetal, objetivando reduzir o teor de óleo de soja residual na torta de lâmina expandida - Lex, levando a um aumento na quantidade de óleo bruto. Observou-se que, nos últimos 4 anos, as médias do teor de óleo residual no Lex foram: 0,97\% em 2012, 1,05\% em 2013, 1,18\% em 2014 e 1,23\% em 2015 (janeiro a março). Dessa forma, um projeto Lean Seis Sigma foi adotado para maximizar a extração de óleo residual, potencializando o retorno financeiro pela venda do óleo bruto e evitando perdas na eficiência do processo.

Palavras-chave: Extração de óleo de soja, otimização, Lean Seis Sigma.

\begin{abstract}
This article aims to describe changes made to an vegetable oil plant, in order to reduce the residual oil content in soybeans expanded blade pie - Lex, leading to an increase in the amount of crude vegetable oil. Over the past four years, an increase in the residual oil percentage has been noticed, the average of the residual oil content in the Lex were $0.97 \%$ in 2012, $1.05 \%$ in 2013, 1.18\% in 2014 and $1.23 \%$ in 2015 (January to March). Thus a Lean Six Sigma project was adopted to maximize residual oil extraction, increasing the financial return from the sale of crude oil and avoiding losses in process efficiency.
\end{abstract}

Keywords: Soy bean extraction, optimization, Lean Six Sigma.

\footnotetext{
${ }^{1}$ UEM - Universidade Estadual de Maringá

${ }^{2}$ UEM - Universidade Estadual de Maringá
} 


\section{Introdução}

Em 2010, foi realizado um investimento para a troca do extrator, no processo de extração de óleos vegetais, alterando o modelo e capacidade do equipamento, passando de um extrator tipo LM, com capacidade de 2.500 TPD (50\% de massa expandida), para um extrator tipo reflex, com funcho fixo, com capacidade de 3.000 TPD (50\% de massa expandida), sendo que para $100 \%$ de massa expandida a capacidade do extrator passa a ser de 3.500 TPD.

As diversas interações de variáveis que formam um processo industrial necessitam estar devidamente alinhadas para que o mesmo funcione. É essencial para o crescimento e competitividade de uma empresa no cenário econômico atual, que o sequenciamento destas atividades seja potencializado e trabalhe alinhado. Devido à alta complexidade e robustez dos processos industriais, evidencia-se uma dificuldade em promover melhorias e aprimoramentos baseados em ajustes de parâmetros do processo (TROMBETA, 2013).

Dessa forma, uma planta industrial com capacidade para processar 2.500 toneladas de soja por dia, sendo 475 toneladas de óleo degomado por dia, enviadas para o refino e 1913 toneladas de farelo por dia, fatura anualmente $\mathrm{R} \$ 313.500 .000,00$ com a venda do óleo e $\mathrm{R} \$$ 631.29.000,00 com a venda do farelo. Sendo lucrativamente mais interessante potencializar a extração de óleo.

A soja contém 18 a $20 \%$ de óleo e o farelo representa cerca de $80 \%$ do material sólido. Sabendo que a torta (estado da soja após passar pelo extrator e antes de passar pelo dessolventizador), apresenta certa quantidade de óleo residual após passar pela extração, notou-se que, nos últimos 4 anos, o teor de óleo residual na torta, o qual deveria ser em média $0,70 \%$ (de acordo com o fabricante do extrator tipo rotocell), passou de 0,97\% em 2012 para 1,23\% em 2015.

\section{Objetivo}

O objetivo é programar ações que resultem no máximo de extração de óleo do grão de soja, contando com poucas ou nenhumas alterações nos equipamentos atualmente instalados na planta, mantendo a média do óleo residual a $0,8 \%$ (limite superior igual a $1 \%$ ).

\section{Metodologia}

O seguinte projeto documentado é proveniente da aplicação das ferramentas do Lean Seis Sigma, o qual representa a criação de valor e eliminação de desperdícios ao longo das etapas do processo, retornando um produto/serviço com a menor variabilidade possível (DOMENECH, 2003).

Primeiro, mapeia-se o processo para eliminar atividades que não agregam valor; depois, encontram-se as causas raízes do problema. Em seguida, busca-se eliminar a variação do processo, obtendo aumento na renda e diminuição dos custos. 


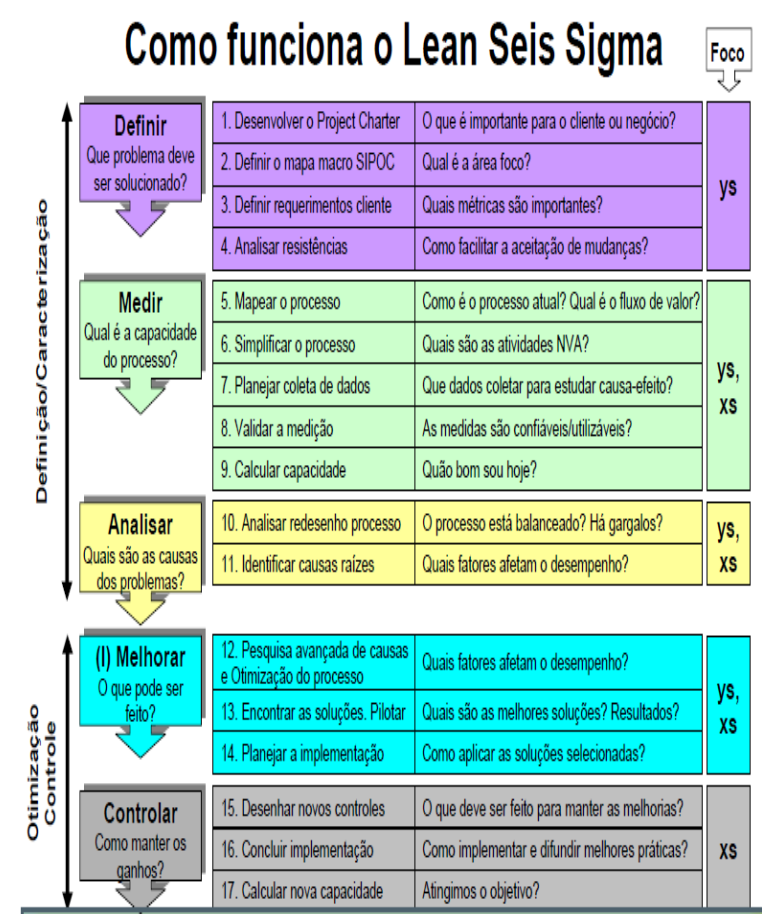

Figura 1: Etapas do Lean Seis Sigma (M. I. DOMENECH)

De acordo com a Figura 1, demonstrada acima, as etapas do projeto foram conduzidas utilizando a ferramenta DMAIC, onde cada sigla significa uma etapa do projeto, com as atividades a serem realizadas:

- Definir: Apresentação da oportunidade;

- Medir: Estudo das Causas Raízes e suas métricas;

- Analisar: Modos de Falha e Análise dos Efeitos (FMEA);

- Melhorar: Ajustes pontuais no processo;

- Controlar: Monitorar a carta de controle do processo por 1 ano.

\section{Aplicação do dmaic}

O ciclo PDCA, concebido por Deming no início do Controle Total da Qualidade, é utilizado como referência em diversos modelos de estratégia que estão envolvidos com a qualidade. O método Seis Sigma utiliza o PDCA como base e aproveita vários dos métodos já comprovados na qualidade, como o diagrama espinha de peixe, o controle estatístico do processo, etc. A maior diferença se dá pela aplicação e o treinamento de seus líderes para que atinjam um alto nível de proficiência na implementação dessas técnicas. As ferramentas utilizadas pelos líderes seguem um padrão simples de melhoria de desempenho, conhecido por DMAIC.

Segundo Watson (2001), a metodologia utilizada pelo Seis Sigma associa um severo enfoque estatístico a ferramentas que são utilizadas tendo em vista a caracterização das fontes da variabilidade para demonstrar como este conhecimento pode controlar e aperfeiçoar os resultados do processo. Para Werkema (2002), o que explica o sucesso do Seis Sigma é a maneira como esta 
estratégia é abordada e sua forma de implementação que é única e muito poderosa. Diversas ferramentas são aplicadas concomitantemente na implementação deste método, para assim garantir o sucesso do mesmo; foco, treinamento, disciplina, dados e não suposições, enfoque estatístico são algumas dessas ferramentas.

\subsection{Definir: apresentação da oportunidade}

Detectou-se a oportunidade de negócio, visto que nos últimos 4 anos (de 2012 a 2015), as médias do teor de óleo residual na saída do extrator de óleos, foram: 0,97\% em 2012, 1,05\% em 2013, 1,18\% em 2014 e 1,23\% em 2015, como observado na Figura 2. Concluindo que havia uma crescente perda de óleo extraído, gerando uma oportunidade de diminuir o teor de óleo residual na torta, levando a um aumento na quantidade de óleo bruto extraído, gerando um aumento no faturamento da cooperativa.

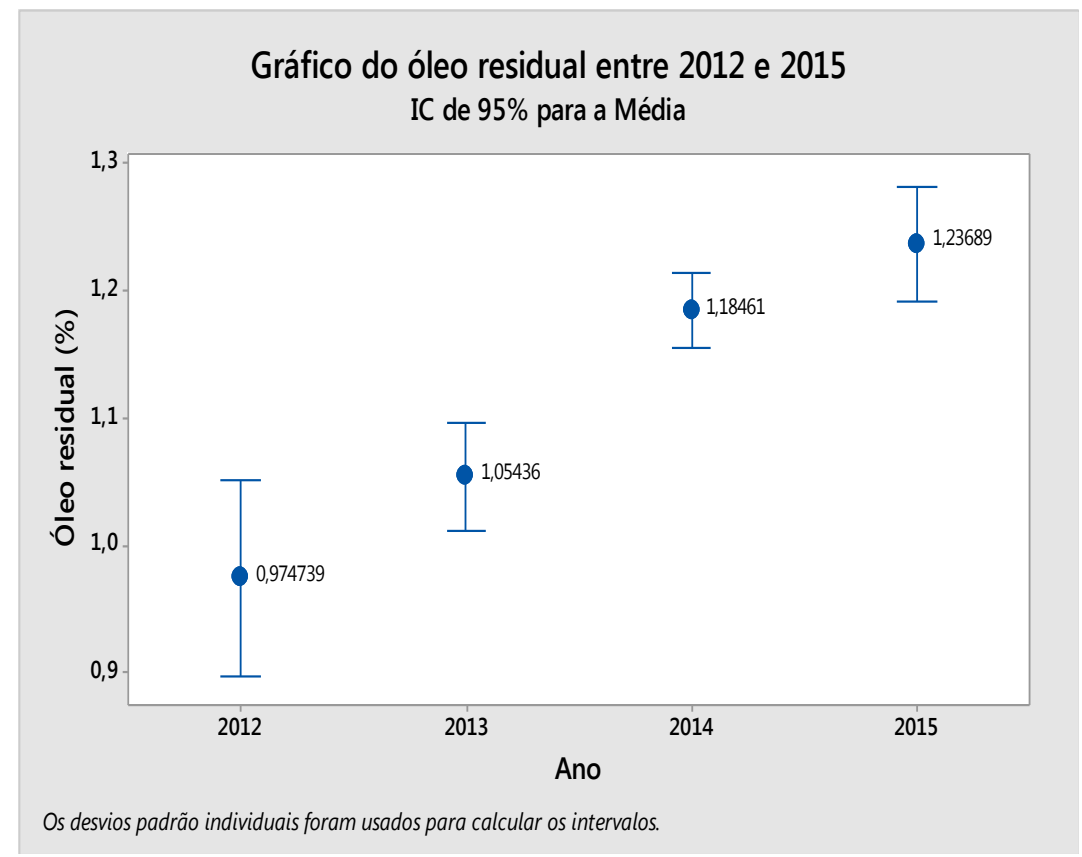

Figura 2: Gráfico de distribuição das médias do óleo residual entre 2012 e 2015

O escopo foi definido através de um fluxo do processo em uma estratificação estatística do processo, iniciando no setor da ressecagem da soja até o dessolventizador (onde ocorre a secagem do farelo da soja), demonstrado na Figura 4. E a restrição do cliente interno é manter a produção prevista de 789.100ton para 2015, sendo 2.500ton/dia e o consumo do solvente para extração (hexano) deve ser $1,05 \mathrm{~L} /$ ton.

O ganho potencial do projeto foi estimado em $\mathrm{R} \$ 3.664 .580,40$, caso atingisse a meta de reduzir o teor de óleo de 1,23\% para 0,80\%, no ano de 2015 (Fonte: Analysis). Este ganho se torna mais elevado, com o passar dos anos, como observado na Figura 3, seguindo o planejamento estratégico da cooperativa, que gradativamente aumenta a quantidade de soja a ser esmagada, agregando valores ao negócio e aumentando o faturamento da cooperativa. 
ISSN: $1415-7314$

ISSN online: $2317-6717$

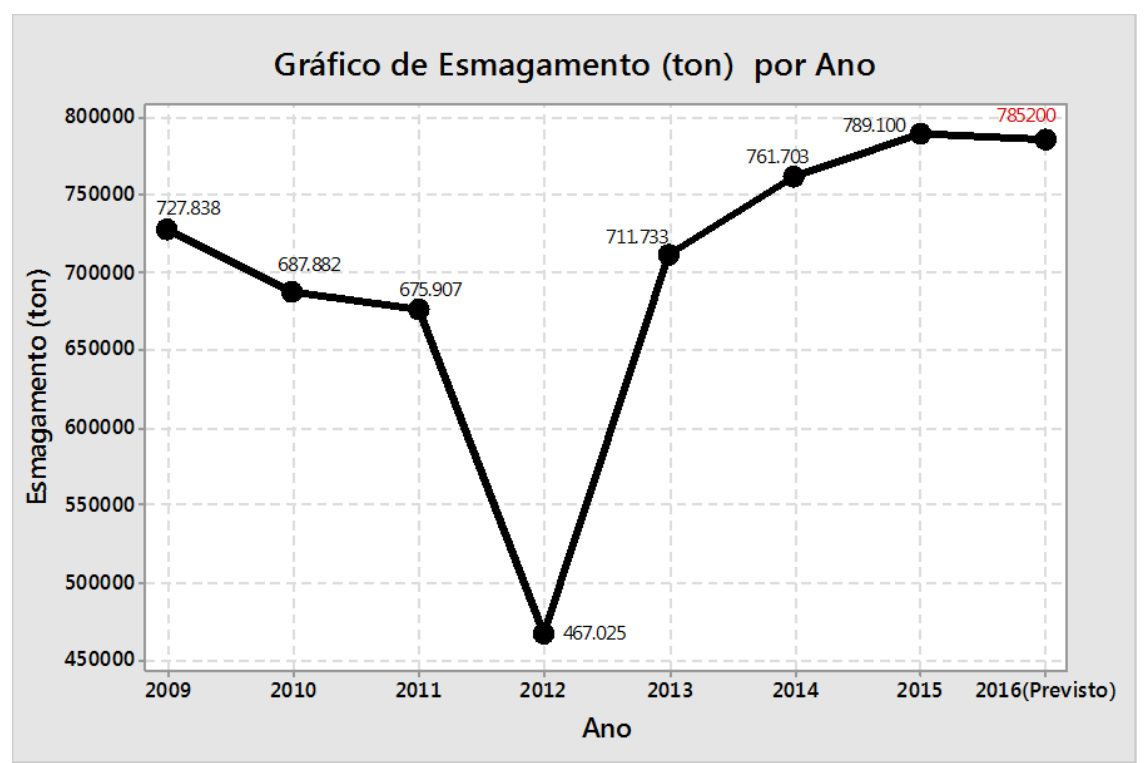

Figura 3: Gráfico de esmagamento (ton) por ano.

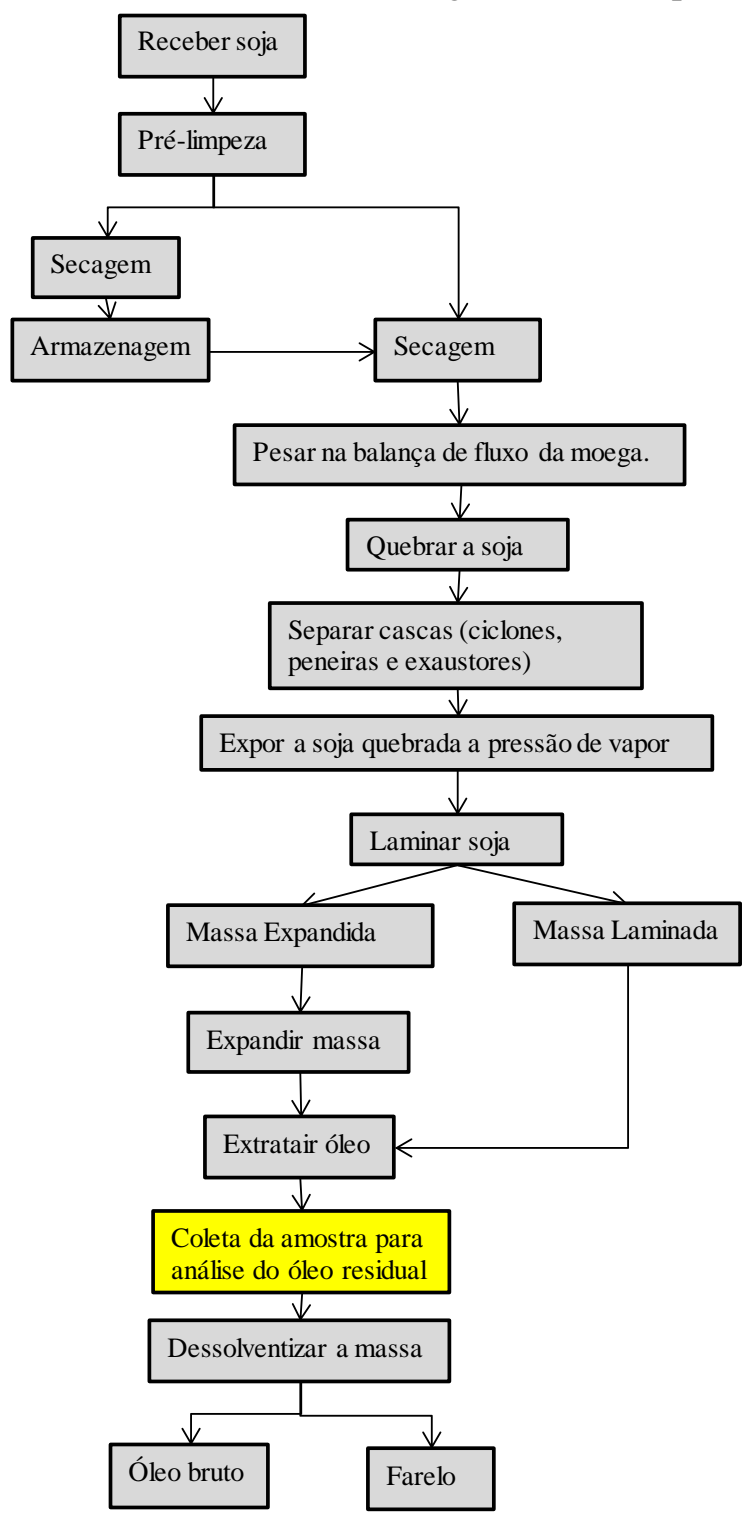

Figura 4: Escopo do Projeto - Processo para obtenção de óleo bruto e farelo desengordurado 


\subsection{Medir: estudo das causas raízes e suas métricas}

De acordo com Carpinetti (2012), Juran conceituou a gestão da qualidade total como nos sistemas de atividades dirigidas para se atingir, empregados com responsabilidades e autoridades, maior faturamento e menor custo.

Levando em consideração essa visão, buscou-se ponderar fatores que poderiam atuar diretamente no percentual do óleo extraído, e a partir disso conferir métricas e parâmetros para padronizar o processo como um todo. Como analisar o banco de dados da fábrica e a confiabilidade das análises do laboratório.

Após a utilização da Matriz Causa-Efeito, juntamente com a equipe de operadores e especialistas do processo, verificou-se que alguns dos principais fatores que influenciam no percentual de óleo na torta são:

- Fragmentos de soja que passam sem receber o banho de solvente (hexano) no extrator;

- Ajustes de pressão nos laminadores;

- Qualidade e porcentagem da massa expandida (uma massa corretamente quebrada será corretamente condicionada e laminada, criando-se uma boa condição para extração do óleo);

- Regulagem das máquinas no geral;

- Manutenção dos equipamentos realizada com eficiência;

- Umidade de entrada da soja;

- Espessura da lâmina;

- Falta de vapor no processo;

- Quebra de equipamentos e, consequentemente, paradas não planejadas;

- Vedação dos laminadores.

Depois de levantadas as possíveis causas raízes, foram realizados alguns ensaios na fábrica, consultorias e benchmarking. Além disso, um 5W2H (What - o que?/Who - quem?/When quando?/Where - onde?/Why - por que?/How - como?/How much - quanto?) foi efetuado. Em suma, chegaram-se as seguintes elucidações:

- O intervalo de espessura das lâminas passou de $[0,25 ; 0,35] \mathrm{mm}$ a $[0,32$ a 0,38$] \mathrm{mm}$, após consultoria do especialista (fabricante do equipamento).

- Mudança estrutural para acréscimo de um redler transportador para levar mais massa expandida para o extrator (antes, apenas 50\% da massa eram expandidas, após a alteração, $70 \%$ da massa passou a ser expandida, resultando posteriormente em uma melhora de $25 \%$ na eficiência da extração do óleo da massa). 


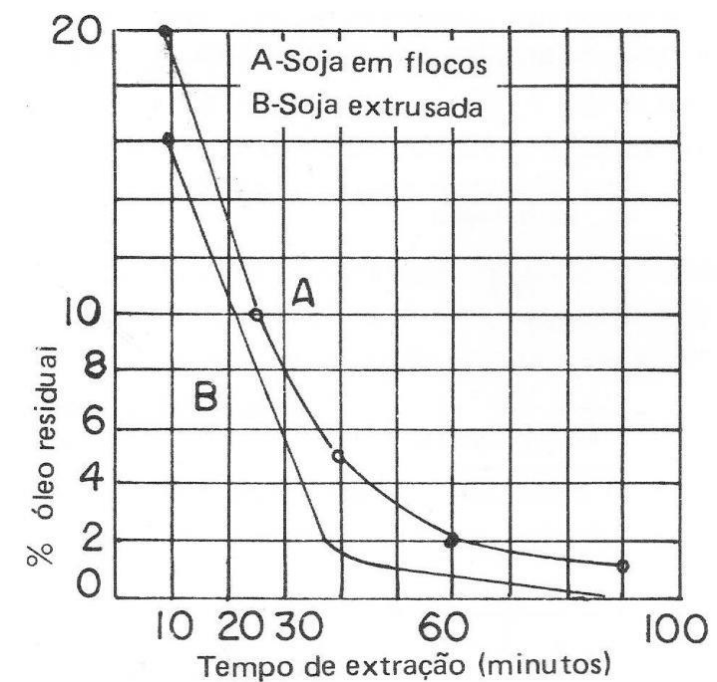

Figura 5: Curvas de porcentagem do óleo residual em função do tempo de extração em soja em flocos e em soja extrusada (RITTER, 1981)

- Programação da reforma dos 12 laminadores atualmente instalados na planta.

- Retífica trimestral dos cilindros laminadores.

- Programação para realização de 59 Kaizens (refere-se a filosofia ou práticas que incidem sobre a melhoria contínua dos processos de manufatura, engenharia, gestão de negócios ou qualquer processo. Quando usado no sentido de negócio e aplicado ao local de trabalho, o kaizen refere-se a atividades que melhorem continuamente todas as funções e envolve todos os funcionários)

\subsection{Analisar}

O objetivo da fase de Analisar é permitir que a equipe do projeto vise oportunidades de melhoria, tendo um olhar mais de perto dos dados para determinar as causas dos problemas do processo e ineficiências. Trata-se de descobrir por que os defeitos são gerados pelas variáveis-chave (identificados na fase medida anteriormente), que são mais susceptíveis de causar a variação do processo. Ainda, a análise estatística é um componente-chave desta fase, utilizada para demonstrar e confirmar essas relações.

Para esse efeito, foi realizada uma análise do layout da planta, tendo como consequência o redesenho do mapa futuro, onde modificações estruturais e melhorias foram apresentadas. Tais como: expansão de elevadores e transportadores para suportar 100\% da massa expandida, bem como a substituição do motor da expander (de $250 \mathrm{cv}$ para $450 \mathrm{cv}$ ); alterações dentro do extrator para que possa ter uma performance melhor de acordo com sua capacidade em relação à quantidade de massa expandida enviada, novos módulos para o secador e regulagens.

Em seguida, buscou-se entender por que o problema está ocorrendo, usando a ferramenta FMEA (Failure Mode and Effects Analysis), a qual possibilita um plano de ação e/ou preventivo/corretivo para todas as possíveis falhas do processo.

No FMEA, após brainstorming da equipe, os seguintes fatores do processo foram destrinchados: 
- Partes de soja inteira dentro do extrator;

- Pressão baixa nos laminadores;

- Qualidade da massa expandida;

- Regulagem das máquinas;

- Dedicação da equipe operacional;

- Manutenção;

- Umidade da soja;

- Água dentro do extrator;

- Experiência profissional;

- Falta de vapor na planta;

- Laminadores e Quebradores mal regulados;

- Regulagens dos condensadores;

- Quebra de máquinas na linha da expander;

- Regulagem da expander;

- Vedação dos laminadores.

Os parâmetros acima tiveram todas as possíveis formas de modo de falha analisadas e pontuadas de acordo com a Severidade, Ocorrência e chance de Detecção, resultando em um indicador chamado RPN - Risk Priority Number ou número de priorização de risco, que é a multiplicação de Severidade, Ocorrência e Detecção. Quanto maior a pontuação RPN, mais alta a prioridade para resolução daquele fator.

Em seguida, ações recomendadas e responsáveis dentro de cada área do processo foram designadas para cada uma das situações.

Subsequentemente, fez-se uso da análise estatística da seleção de Clusters, para que a melhor configuração de todos os ajustes fosse encontrada. O propósito da Análise de Cluster é buscar uma classificação de acordo com as relações que a amostra apresenta, formando grupos de objetos por similaridade. Portanto, objetiva-se aqui, encontrar qual a melhor combinação dos 7 x's - fatores que, comprovadamente afetam o processo - que resulta no teor de óleo residual mais baixo (ou seja, com a média $0,8 \%$ ). Nessa análise, os parâmetros foram separados em 3 turnos, sendo feita uma média aritmética de cada ajuste; os dados coletados são referentes a 6 meses de banco de dados e as variáveis x's analisadas foram: média da espessura da lâmina, umidade da soja na balança de entrada do processo, temperatura do condicionador, granulometria, pressão de vapor da expander, ajuste da corrente da expander e porcentagem de micela da bomba de saída do extrator. 


\section{Gráfico de Intervalos dos Indicadores do Processo IC de $95 \%$ para a Média}

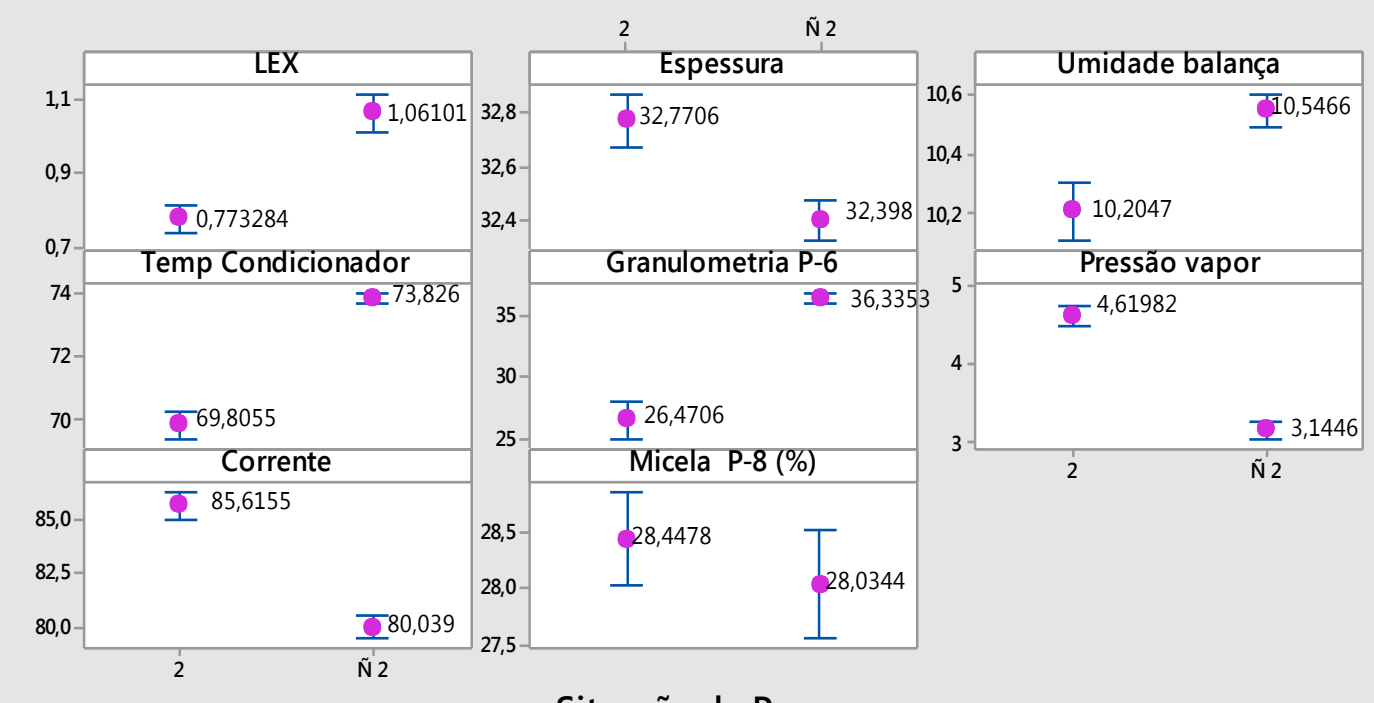

Situação do Processo

Os desvios padrão individuais foram usados para calcular os intervalos.

Figura 6: Análise de Clusters

O gráfico acima, demonstrado na figura 6, ilustra a última parte da Análise de Clusters, onde dois grandes subgrupos foram divididos. O grupo "N 2" representa todos os outros clusters agrupados, e o grupo "2" mostra a melhor configuração para cada parâmetro.

Em suma, essa análise indicou a comprovação estatística da suspeita de melhor configuração dos ajustes dos 7 parâmetros que mais impactam no output do processo - teor de óleo residual.

Nesta etapa, o processo foi analisado, e as principais causas de variação detectadas e comprovadas estatisticamente. Em seguida, o processo deve ser aprimorado através da eliminação das causas raízes.

\subsection{Melhorar}

Uma vez que as causas raízes foram identificadas, é hora de desenvolver, programar e validar métodos para chegar ao melhor desempenho do processo. Posteriormente, como parte do Seis Sigma, é preciso garantir que os resultados estão sendo alcançados antes que a adesão total possa ser efetivada.

Nesta etapa, houve o planejamento de 22 ações para serem implementadas na parada da entressafra, a qual teve duração de 1 mês, onde todas as alterações de layout do mapa futuro foram colocadas em prática.

Posteriormente, uma das soluções priorizadas foi a realização de um plano para TPM (Total Productive Maintenance ou Manutenção Produtiva Total). O plano consiste na preparação de um checklist das atividades da rotina dos operadores; exposições de Lições de Um Ponto - indicando o 
passo a passo de todos os procedimentos; figuras dos equipamentos com identificação de cada ponto, para ilustrar a gestão visual da rotina; padronização de operações de comunicação e, por último, a contratação de um mecânico para trabalhar com dedicação exclusiva aos cuidados dos laminadores apontados como uma das causas raízes da variação do teor de óleo residual.

Frente à análise de custo-benefício, a ação da contratação de um mecânico para tratar especificamente dos laminadores, veio por meio da comprovação da redução do lead time do subprocesso "solicitação de serviço para mecânico". Antes, esse subprocesso continha 7 etapas. Após a entrada do manutentor, o processo passou a ter 4 etapas, consequentemente eliminando 3 NVAs (Non Valuable Action), resultando na diminuição do lead de 3 dias para $2 \mathrm{~h}$.

Uma vez que as soluções implementadas são comprovadas com ganhos mensuráveis quantitativamente, move-se para a Etapa Controlar.

\subsection{Controlar}

A etapa Controlar marca o final do projeto. Nessa fase, as melhorias já estão implementadas e devem ser consolidadas.

Desta forma, ocorreu a padronização de operações, que por meio de um 5W2H foi concebido o "o quê, por que, onde, quem, quando, como e quanto custa", com o objetivo de facilitar e melhorar a comunicação entre operadores e o manutentor. Em seguida, a realização de um treinamento operacional para instruir todos os envolvidos nesse procedimento.

Foram desenvolvidas a Matriz de Controle e o Plano OCAP (Out of Control Action Plan) para 31 possíveis erros do processo e as ações que devem ser tomadas caso esses erros aconteçam.

Para analisar e monitorar o processo utiliza-se o CEP: Controle Estatístico do Processo. O controle estatístico pode ser considerado como uma ferramenta preventiva ou corretiva. Considera-se como implantar o CEP em uma empresa para que os critérios de controle sejam realmente utilizados para monitorização e melhoria. Nesse sentido, o CEP é uma das ferramentas que permite manter a variável y (teor de óleo residual na torta) dentro dos limites desejados - USL (limite superior) = $1,00 \%$ e média $=0,8 \%$. Para isto deve ser mantido sob controle os xs poucos e vitais.

O Controle Estatístico do processo - CEP, demonstrado na Figura 7, foi utilizado os resultados desde o inicio do projeto, separando por períodos que ocorreram grandes alterações na produção. As ações e resultados durante o projeto encontra-se abaixo: 


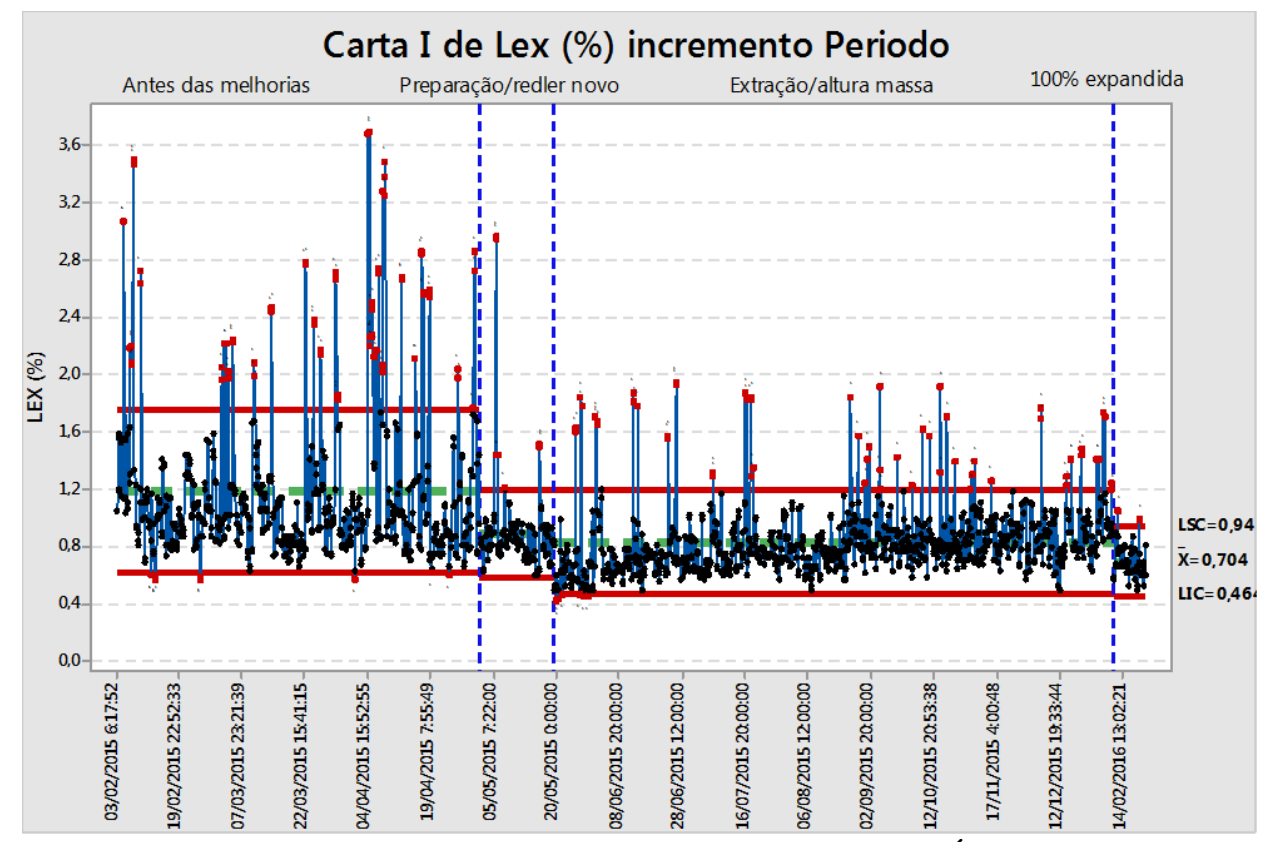

Figura 7: Controle Estatístico do Processo - Teor de Óleo Residual

É notável que as causas especiais ainda estão presentes. No entanto, foram identificadas e estão sendo atacadas desde o início do projeto.

Para concluir, é importante enfatizar todas as etapas finalizadas nessa fase:

- FMEA revisado;

- Novo Mapa Futuro;

- TPM institucionalizado;

- Matriz de Controle e Plano OCAP;

- Novo procedimento operacional;

- Processo entregue nas mãos do responsável;

- Revisão dos ganhos financeiros;

- Aprovação da gerência para conclusão do projeto.

Por fim, a equipe e os stakeholders são reconhecidos e as diretrizes para monitoramento em longo prazo definidas.

\section{Conclusão}

Em todas as etapas do DMAIC (Definir, Medir, Analisar, Melhorar e Controlar), suspeitas e hipóteses devem ser comprovadas com dados. E a equipe deve não somente provar que esses fatores estão presentes, mas também confirmar que mudanças nesses parâmetros irão afetar substancialmente o y do processo, ou seja, o output. 
Após a finalização do projeto Lean Seis Sigma, com o objetivo de redução do teor de óleo residual, observa-se que os resultados são bastante expressivos favoravelmente à meta do projeto. A média está dentro dos limites de controle e perto do limite inferior de especificação, o que significa que quanto menor o teor de óleo, maior a eficiência do processo e, portanto, maior retorno financeiro.

\section{Bibliografia}

ANDRIETTA, João Marcos; MIGUEL, Paulo Augusto Cauchick. A importância do método Seis Sigma na Gestão da Qualidade Analisada sob uma Abordagem Teórica. Revista de Ciência \& $\begin{array}{lllllll}\text { Tecnologia, } & \text { v.11, } & \text { n.20 } & \text { p } & 91-98 . & \text { Disponível } & \text { em }\end{array}$ www.unimep.br/phpg/editora/revistaspdf/rct20art11.pdf. Acesso em 08/12/15.

CARPINETTI, L. C. R., 2012. Gestão da Qualidade Conceitos e Técnicas. São Paulo: Editora Atlas. DOMENECH, C.H. 2003. Disponível em http://www.midomenech.com.br/treinamentos.asp. Acesso em 11/11/15.

GYGI, C. WILliAMS, B. DeCARLO, N. 2005. Six Sigma for Dummies. 2a Edição. Paperback. P $50-55$.

MOHD, K. A. 2016. Part II: Understanding Six Sigma and DMAIC methodology. APO - Asian Productivity Organization. Disponível em http://www.apo-tokyo.org/productivity/pmtt_006.htm. Acesso em 10/02/16.

RITTER, H. 1981. Condicionamento da Soja para Extração por Processos de Solvente. In: A Soja no Brasil. Edição de Shiro Miyasaka e Júlio César Medina. Campinas: ITAL.

SWAN, E. 2015. The basics of Lean Six Sigma. Disponível em https://goleansixsigma.com/thebasics-of-lean-six-sigma/. Acesso em 11/02/16.

TROMBETA, Alessandro. 2013. Aplicação de um modelo matemático para análise do processo de extração de óleo de soja em um extrator de esteira. Dissertação de Mestrado, Universidade Estadual de Maringá.

WATSON, G. H. 2001. Cycles of leaming: observations of Jack Welsh. ASQ Publication, Millwaukee. P 45-58.

WERKEMA, Maria Cristina. 2002. Criando a cultura Seis Sigma. Rio de Janeiro: Qualitymark. WIESENFELDER, H. 2011. DMAIC Phase 3: Analyze. Bright Hub Project Management. Disponível em http://www.brighthubpm.com/six-sigma/24789-dmaic-phase-three-the-analyzephase/. Acesso em 10/02/16. 